\title{
Carbon Capture and Storage System Using Pinch Design Method
}

\author{
Renanto Handogo ${ }^{1 *}$ \\ ${ }^{1}$ Chemical Engineering Department, Institut Teknologi Sepuluh Nopember, Surabaya 60111, East Java, Indonesia
}

\begin{abstract}
Carbon capture and storage (CCS) have been investigated for a long time. It was intended to reduce carbon dioxide $\left(\mathrm{CO}_{2}\right)$ in the atmosphere due to fossil fuel combustion in power generation and industrial processes. $\mathrm{CO}_{2}$ is captured and stored in various geological formations. The problem here is to match between source and sink such that alternative storage and unutilized storage capacities are minimum. Pinch Design Method as has been proposed by was used in this work. The concept is overwhelming that it can be used other than in the heat exchanger networks, such as in the water system design, mass exchanger networks and many other processes. Initially this concept was applied to carbon capture and storage but with no exact pairing between sources and sinks as proposed in this work using grid diagram as commonly shown in other processes. This work can point out the exact pairing between sources and sinks, and within the given time frame. A four different cases are investigated where the time difference between the starting time of $\mathrm{CO}_{2}$ generated in the source and the beginning of sink availability. A value of $0,5,10$ and 15 years are chosen to evaluate the amount of $\mathrm{CO}_{2}$ that has to be stored and the amount of unutilized storage capacity. The case study has been prepared with 5 sources and 3 sinks. The result shows that the larger time difference the larger alternative storage and unutilized storage capacities. Therefore, having a shorter time difference will be more acceptable in the design CCS system.
\end{abstract}

\section{Introduction}

Global warming is an issue that is being discussed in the international world lately. Global warming is characterized by rising global average temperatures on the earth's surface. Studies show that the average global air temperature has increased by about $0.5-1.0^{\circ} \mathrm{F}(0.3-$ $0.6^{\circ} \mathrm{C}$ ) over the past century. This is the largest rise in surface temperature in the last 1,000 years and scientists predict a larger increase will occur over a century. This heating is mostly caused by increases in greenhouse gases, especially carbon dioxide $\left(\mathrm{CO}_{2}\right)$ and methane over the earth's atmosphere caused by the burning of fossil fuels, industrial activities, agriculture and deforestation. One solution that can be applied quickly and on a large scale is to use Carbon Capture and Storage (CCS) technology.

According to the ESDM Ministry, CCS is one of the climate change mitigation technologies that has the potential to reduce large-scale $\mathrm{CO}_{2}$ emissions resulting from burning fossil fuels. CCS is an effort with a technique approach to capture carbon and store it in a safer form. This technology is a series of activities starting from capturing $\mathrm{CO}_{2}$ sources such as natural gas processing facilities and power plants, then transporting them to $\mathrm{CO}_{2}$ storage locations in appropriate geological sinks.

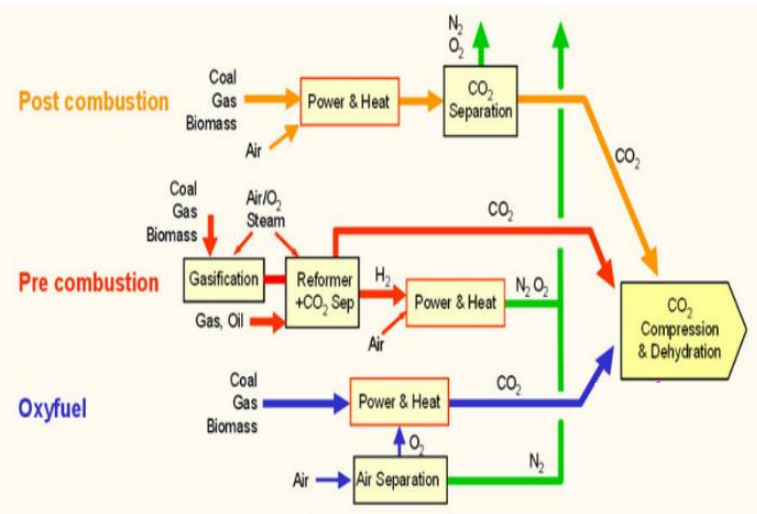

Fig. 1. Ways of catching $\mathrm{CO}_{2}$ from industries (post combustion, pre combustion, and Combustion) (IPCC, 2005)

In the CCS process, the process of matching between the source and storage of $\mathrm{CO}_{2}$ are often subjected to various constraints, such as storage capacity availability, the location of the source and storage availability, and the time source and storage availability. These problems

* Corresponding author : renanto@chem-eng.its.ac.id 
can be solved with a design technology that is pinch technology that can provide an minimum alternative and unultilized storage. Pinch technology is built on the laws of thermodynamic heat transfer. This technology is dominated by the design of Heat Exchanger Network (HEN) which provides optimum energy cost savings. The concept is overwhelming that it can be used other than in

the heat HEN, such as in the water system design, Mass Exchanger Networks (MEN) and many other processes. In water design system exactly cooling water system, the performance of a cooling tower is maximized by maximizing the inlet temperature to the cooling tower and minimizing the inlet flowrate. The role of the pinch technology here is for getting minimum cooling water flowrate (Smith, 2005). By MEN, we mean the systematic generation of a cost-effective network of mass exchangers with the goal of transferring certain species from a set of rich streams to a set of lean streams. A mass exchanger can be virtually any countercurrent, direct-contact mass-transfer operation that uses a Mass-Separating Agents (MSA) (eg, absorption, desorption, adsorption, liquid-liquid extraction, leaching, and ion exchange) (El-Halwagi and Manousiouthakis, 1989).

Initially this concept was applied to carbon capture and storage but with no exact pairing between sources and sinks as proposed in this work using grid diagram as commonly shown in other processes (Raymond et.al, 2013). This work can point out the exact pairing between sources and sinks, and within the given time frame. The pinch calculations in this work are performed with composite curve and Carbon Storage Cascade Analysis (CSCA). Just like in HEN, the composite curve CCS will consist of two lines, namely a source line as hot streams and a sink line as cold streams. By shifting the sink line until it gets pinch according to the set time difference it will get the number of alternative storage and unutilized storage.

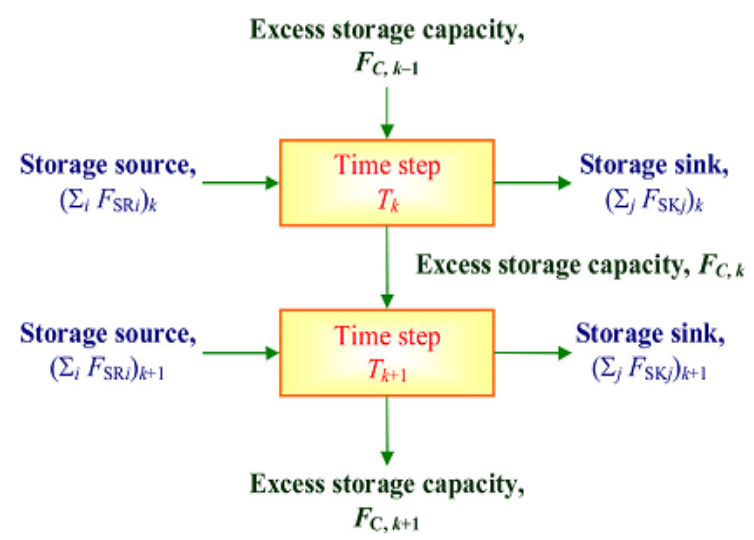

Fig. 2. Concept of Cascade Analysis (Raymond et.al, 2013)

While the cascade analysis as shown in figure 2 is based on the cumulative amount of $\mathrm{CO}_{2}$ load at a certain time interval from the first year until the last year. The biggest deficit in an interval is as alternative storage and the value is rearranged as surplus value at the beginning of the year so there is no deficit at each interval and will be obtained at a time with a value of 0 called a pinch.
The amount of surplus in the last year is as unutilized storage.

\section{Study Description}

\subsection{Data Collections}

Data collection is very important with respect to the reality of data in the field, as the success of the research results is influenced by proper data retrieval. Until now, in Indonesia the companies still have not implemented CCS system. Therefore, in order to obtain the data (case) which almost resembles the field situation, it is necessary to study literature as a comparison.

\subsection{Create a Grid Diagram on Each Variable}

The grid diagram is used to present the results of the Pinch Design Method.

\section{Results and Discussion}

\subsection{Data Collections}

From the study of literature, then in this study were given four variables namely dT (time difference) 0 years, 5 years, 10 years, and 15 years. The following data will be used in this research.

Table 1. Sources Data

\begin{tabular}{|c|c|c|c|c|}
\hline Source & $\begin{array}{c}\mathbf{C O}_{2} \\
\text { flowrate } \\
(\mathbf{M t} / \mathbf{y})\end{array}$ & $\begin{array}{c}\mathbf{C O}_{2} \\
\text { load } \\
(\mathbf{M t})\end{array}$ & $\begin{array}{c}\text { Start } \\
\text { time } \\
(\mathbf{y})\end{array}$ & $\begin{array}{c}\text { End } \\
\text { Time } \\
(\mathbf{y})\end{array}$ \\
\hline 1 & 15 & 300 & 0 & 20 \\
\hline 2 & 5 & 150 & 0 & 30 \\
\hline 3 & 5 & 150 & 0 & 30 \\
\hline 4 & 20 & 400 & 20 & 40 \\
\hline 5 & 10 & 400 & 30 & 70 \\
\hline Total & $\mathrm{n} / \mathrm{a}$ & 1400 & $\mathrm{n} / \mathrm{a}$ & $\mathrm{n} / \mathrm{a}$ \\
\hline
\end{tabular}

Table 2. Sinks Data

\begin{tabular}{|c|c|c|c|c|}
\hline Sink & $\begin{array}{c}\text { Injectiv } \\
\text { ity } \\
\text { (Mt/y) }\end{array}$ & $\begin{array}{c}\text { Storage } \\
\text { capacity } \\
(\mathbf{M t})\end{array}$ & $\begin{array}{c}\text { Earliest } \\
\text { time } \\
\text { available } \\
\text { (y) }\end{array}$ & $\begin{array}{c}\text { Characte } \\
\text { ristic end } \\
\text { time (y) }\end{array}$ \\
\hline 1 & 20 & 900 & 10 & 55 \\
\hline 2 & 15 & 750 & 20 & 70 \\
\hline 3 & 10 & 550 & 30 & 85 \\
\hline Total & $\mathrm{n} / \mathrm{a}$ & 2200 & $\mathrm{n} / \mathrm{a}$ & $\mathrm{n} / \mathrm{a}$ \\
\hline
\end{tabular}

\subsection{Optimization Based on Multi Period}

At each time interval, each source portion is combined into a composite curve section, by adding the line diagonally. Substitution of the composite part will start from the end of the previous section, which will be converted into a source composite curve. Similarly, the composite sink curve is also done the same as the source composite curve. 


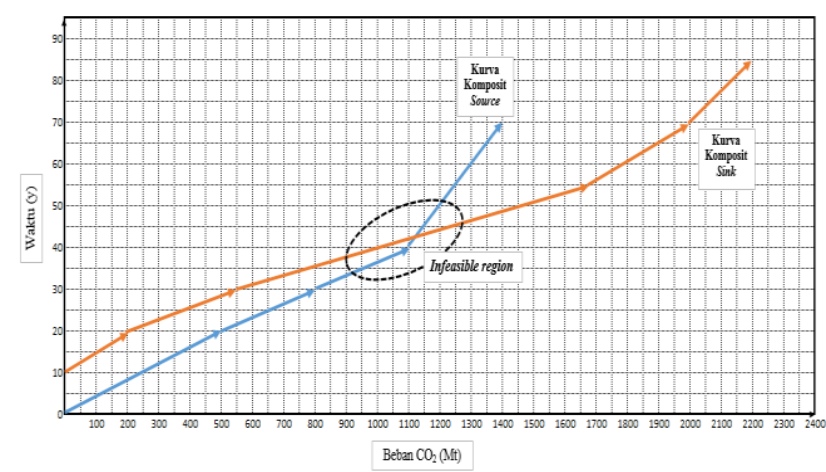

Fig. 3. Merging composite source and sink curves

In the figure 3 , it shows that the relative position of the composite curve indicates an overlap between the source and sink composite curves. It is not possible in the real event, so it is called an infeasible region. Part of the composite sink curve is to the left of the source composite curve which means that the sink is only ready once the source is available.

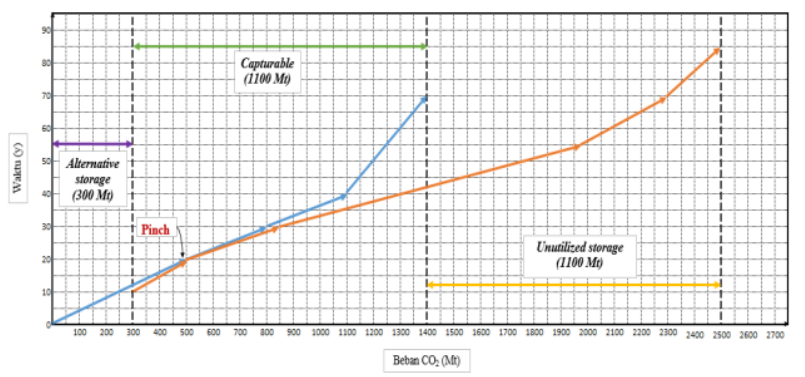

Fig. 4. Merging composite source and sink curves with Pinch 0 year

The deficit may be interpreted as delaying the decision to capture $\mathrm{CO}_{2}$, until internal sink time (storage) is readily available for use. Areas where the two composite curves overlap each other imply that $1100 \mathrm{Mt}$ of $\mathrm{CO}_{2}$ can be sent from source to available sinks. The composite curve shows that within 20 years the pinch point with the time difference is 0 . In other words, the two composite curve encounters are at the pinch point. Further observation on the pinch diagram is the availability of a storage capacity of $1100 \mathrm{Mt}$ which is not used as a sink from the source. Captured $\mathrm{CO}_{2}$ of $1100 \mathrm{Mt}$ presented that $50 \%$ of the $2200 \mathrm{Mt}$ that can be stored in the 3 sinks. The same is shown by table 3 which is the cascade table for the 0 year difference show the pinch in the 20 year. The cascade table also show the same alternative storage of $300 \mathrm{Mt}$ and unutilized storage of $1100 \mathrm{Mt}$.
Table 3. Cascade analysis for source and sink with 0 year time difference

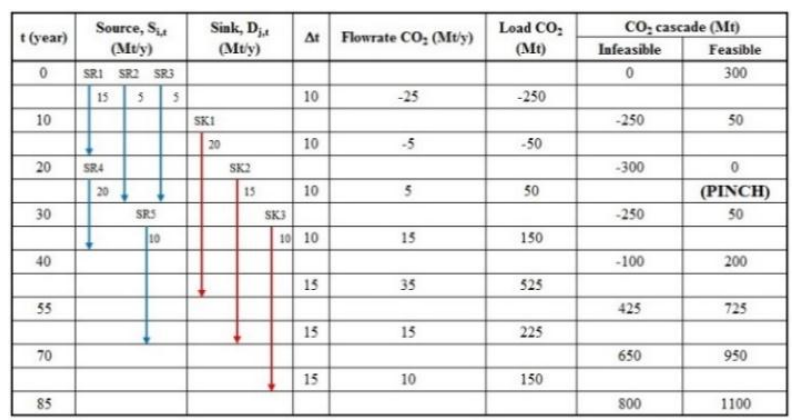

Pinch point on the diagram divides the system into 2 regions. Before pinch point, there are areas where $\mathrm{CO}_{2}$ requires storage. While after pinch point, there is excess storage. The above scenario is one of the problems that occur in this network, because almost all potential storage locations will experience some delay before the sink receives $\mathrm{CO}_{2}$ from source. From figure 4 shows below the composite sink curve starts in the 10th year. In other words, alternative storage should be sought in the first 10 years of operation. If no external storage is available, then the decision to capture $\mathrm{CO}_{2}$ must be suspended in the 10th year, when the internal storage is ready for use.

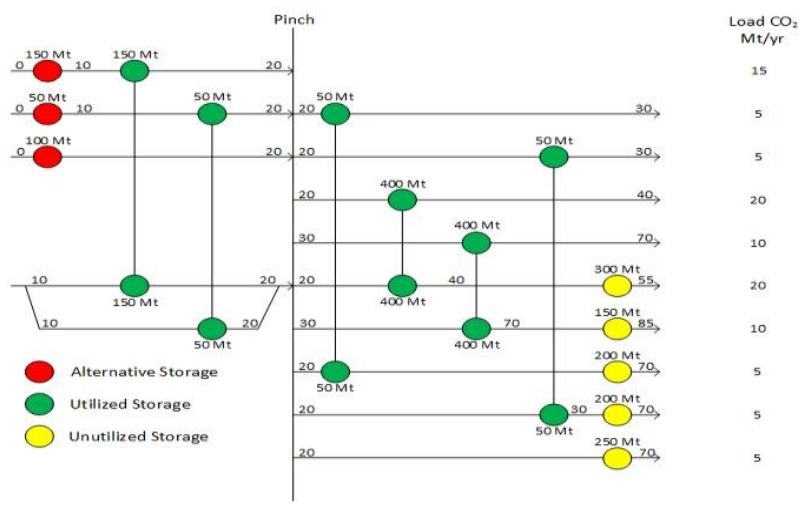

Fig. 5. CCS grid diagrams with 0 year Pinch time difference

Figure 5 shows that sink 1 receives $\mathrm{CO}_{2}$ from source 1,2 , and 4 in the 10 to 40 year timeframe. Meanwhile, $\mathrm{CO}_{2}$ from partially source 2 , and 3 is sent to sink 2 that ends up to year 70 . Then sink 3 is receives $\mathrm{CO}_{2}$ from source 5 in the 30 to 70 timeframe. From the grid diagram obtained the number of alternative and unutilized storage is suitable with the composite curve and cascade analysis calculations so that the pairing done with this grid diagram and resulted the exact pairing. However, in a plant occurring it is not possible to match pinch points with a 0 year time difference. From this research, discuss the optimization network with various time difference variables of 5, 10 and 15 years. This is based on real events in a carbon capture plant that 
experiences delays in source delivery to sinks or experienced $\mathrm{CO}_{2}$ escapes from this system.

In the next time difference variable that is pinch point with 5 year time difference. In the figure 6 shows that $\mathrm{CO}_{2}$ from various sources can be captured only $950 \mathrm{Mt}$ of a total of 1,400 Mt. This leads to an increase in $\mathrm{CO}_{2}$ deficit captured and requires another alternate storage of $450 \mathrm{Mt}$. So does the unused storage capacity of 1,250 Mt. In this case there is a pinch point with a 5-year time difference that is at the time of the year 20-25. The captured $\mathrm{CO}_{2}$ of $950 \mathrm{Mt}$ presents that $43.2 \%$ of the 2,200 Mt that can be stored in the 3 sinks. The same is shown by table 4 which is the cascade table for the 5 year difference show the pinch in the 20-25 year. The cascade table also show the same alternative storage of $450 \mathrm{Mt}$ and unutilized storage of $1250 \mathrm{Mt}$.

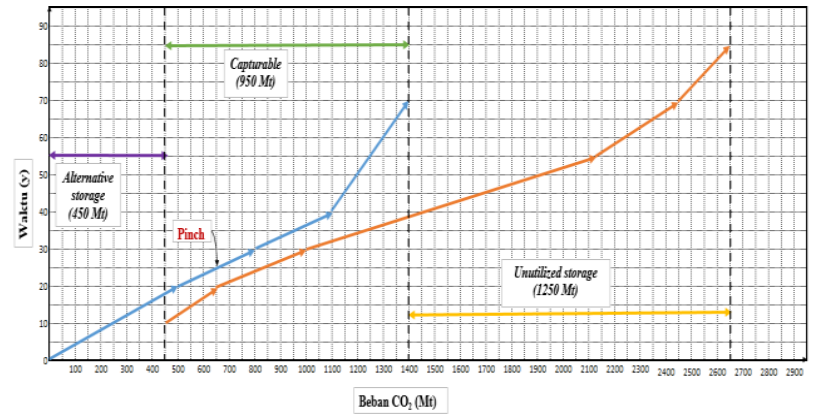

Fig. 6. Merging composite source and sink curves with Pinch 5 year

Table 4. Cascade analysis for source and sink with difference time of 5 years

\begin{tabular}{|c|c|c|c|c|c|c|c|c|c|c|}
\hline \multirow{2}{*}{$t$ (year) } & \multirow{2}{*}{\multicolumn{3}{|c|}{$\begin{array}{c}\text { Source, } \mathbf{S}_{\mathbf{i}, t} \\
\left(\mathbf{M} t \mathbf{y}^{\mathbf{n}}\right)\end{array}$}} & \multirow{2}{*}{\multicolumn{2}{|c|}{$\begin{array}{c}\text { Sink, } \mathbf{D}_{j, t} \\
(\mathbf{M} t \mathbf{y})\end{array}$}} & \multirow{2}{*}{$\Delta t$} & \multirow{2}{*}{ Flowrate $\mathrm{CO}_{2}(\mathrm{Mt} t \mathrm{y})$} & \multirow{2}{*}{$\begin{array}{c}\text { Load CO, } \\
(\mathrm{Mt})\end{array}$} & \multicolumn{2}{|c|}{$\mathrm{CO}_{2}$ cascade $(\mathrm{MIt})$} \\
\hline & & & & & & & & & Infeasible & Feasible \\
\hline \multirow[t]{2}{*}{0} & SRI S & $\mathrm{SR2}$ & SR3 & & & & & & 0 & 450 \\
\hline & 15 & 5 & 5 & & & 15 & -25 & -375 & & \\
\hline \multirow[t]{2}{*}{15} & & & & SK1 & & & & & -375 & 75 \\
\hline & & & & $T_{20}$ & & 5 & -5 & -25 & & \\
\hline \multirow[t]{2}{*}{20} & SRA & & & & & & & & -400 & 50 \\
\hline & 20 & & & & & 5 & -10 & -50 & & \\
\hline \multirow[t]{2}{*}{25} & & & & & $\mathrm{SK2} 2$ & & & & -450 & 0 \\
\hline & & & & & 15 & 5 & 5 & 25 & & (PINCH) \\
\hline \multirow[t]{2}{*}{30} & & SRS & & & & & & & -425 & 25 \\
\hline & & & & & & 5 & 5 & 25 & & \\
\hline \multirow[t]{2}{*}{35} & & & & & SK3 & & & & -400 & 50 \\
\hline & & & & & 10 & 5 & 15 & 75 & & \\
\hline \multirow[t]{2}{*}{40} & & & & & & & & & -325 & 125 \\
\hline & & & & & & 20 & 35 & 700 & & \\
\hline \multirow[t]{2}{*}{60} & & & & & & & & & 375 & 825 \\
\hline & & & & & & 10 & 15 & 150 & & \\
\hline \multirow[t]{2}{*}{70} & & & & & & & & & 525 & 975 \\
\hline & & & & & & 5 & 25 & 125 & & \\
\hline \multirow[t]{2}{*}{75} & & & & & & & & & 650 & 1100 \\
\hline & & & & & & 15 & 10 & 150 & & \\
\hline 90 & & & & & & & & & 800 & 1250 \\
\hline
\end{tabular}

Because of the time difference difference, the pairing obtained on the grid diagram is different too as shown in figure 7. Sink 1 receives $\mathrm{CO}_{2}$ from source 1,3, and 4 in the 10 to 35 year timeframe. Meanwhile, $\mathrm{CO}_{2}$ from partially source 2,3 , and 5 is sent to sink 2 that ends up to year 65 . Then sink 3 available from year 30 to year 85 is an available storage but no injektivity from source. This is because the amount of $\mathrm{CO}_{2}$ from the source that existed at the time over the pinch has been sufficiently stored in sinks 1 and 2 . The grid diagram obtained the number of alternative and unutilized storage which is consistent with the composite curve and cascade analysis calculations, so that the pairing can be done using this grid diagram and resulted in the the exact pairing.

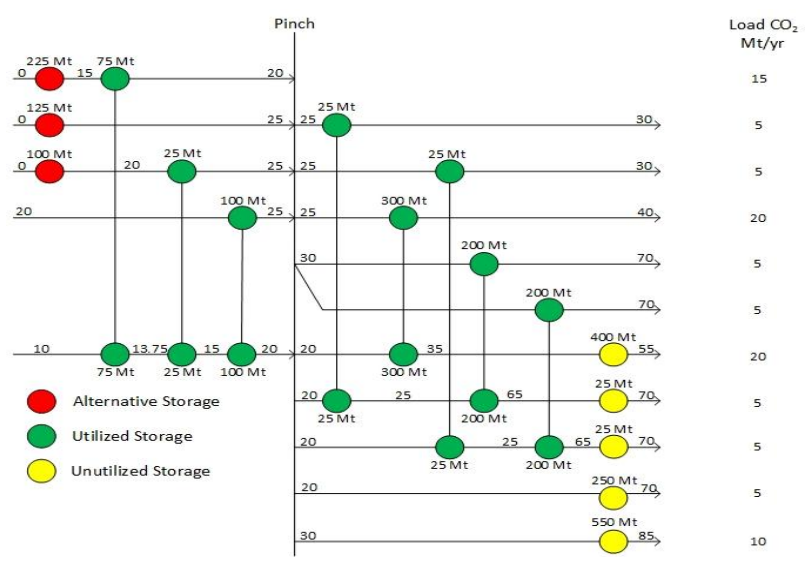

Fig. 7. CCS grid diagram with 5 year Pinch time difference

Table 5. Cascade analysis for source and sink with difference time of 10 years.

\begin{tabular}{|c|c|c|c|c|c|c|c|c|c|}
\hline \multirow{4}{*}{$\begin{array}{c}\mathbf{t} \text { (year) } \\
0\end{array}$} & \multirow{2}{*}{\multicolumn{3}{|c|}{$\begin{array}{c}\text { Source, } \mathbf{S}_{\mathrm{t}, \mathrm{t}} \\
\text { (Mtty) }\end{array}$}} & \multirow{2}{*}{$\begin{array}{c}\text { Sink, } \mathbf{D}_{\mathbf{j},} \\
\text { (Mty) }\end{array}$} & \multirow{3}{*}{$\Delta t$} & \multirow{2}{*}{ Flowrate $\mathrm{CO}_{2}$ (Mty) } & \multirow{2}{*}{$\begin{array}{c}\text { Load CO, } \\
\text { (Mit) }\end{array}$} & \multicolumn{2}{|c|}{$\mathrm{CO}_{2}$ cascade (Mt) } \\
\hline & & & & & & & & \multirow{2}{*}{$\frac{\text { Infeasible }}{0}$} & \multirow{2}{*}{$\begin{array}{c}\text { Feasible } \\
600\end{array}$} \\
\hline & SRI & SR2 5 & & & & & & & \\
\hline & 115 & 5 & 5 & & 20 & -25 & -500 & & \\
\hline \multirow[t]{2}{*}{20} & SRA & & & SK1 & & & & -500 & 100 \\
\hline & 20 & & & 20 & 10 & -10 & -100 & & \\
\hline \multirow[t]{2}{*}{30} & & SRS & & \begin{tabular}{|l|}
$\mathrm{SK} 2$ \\
\end{tabular} & & & & -600 & 0 \\
\hline & & 10 & & 13 & 10 & 5 & 50 & & (PINCH) \\
\hline \multirow[t]{2}{*}{40} & & & & $5 \times 3$ & & & & -550 & 50 \\
\hline & & & & 1 & 25 & 35 & 875 & & \\
\hline \multirow[t]{2}{*}{65} & & & & & & & & 325 & 925 \\
\hline & & & & & 5 & 15 & 75 & & \\
\hline \multirow[t]{2}{*}{70} & & & & & & & & 400 & 1000 \\
\hline & & & & & 10 & 25 & 250 & & \\
\hline \multirow[t]{2}{*}{80} & & & & & & & & 650 & 1250 \\
\hline & & & & & 15 & 10 & 150 & & \\
\hline 95 & & & & & & & & 800 & 1400 \\
\hline
\end{tabular}

In the next time difference variable that is pinch point with 10 year time difference. In this cascade table for the 10 year difference show the pinch in the 20-30 year. The cascade table also show the alternative storage of $600 \mathrm{Mt}$ and unutilized storage of $1400 \mathrm{Mt}$. The captured $\mathrm{CO}_{2}$ of $800 \mathrm{Mt}$ presents that $36.4 \%$ of the $2200 \mathrm{Mt}$ that can be stored in the 3 sinks. The pairing obtained sink 1 as shown in figure 8 receives $\mathrm{CO}_{2}$ only from source 4 in the 10 to 30 year timeframe and sink 2 receives $\mathrm{CO}_{2}$ only from source 5 in the 20 to 60 year timeframe. The grid diagram obtained the number of alternative and unutilized storage is suitable with the cascade analysis calculations so that the pairing done with this grid diagram and resulted the exact pairing.

In the last time difference variable that is pinch point with 15 year time difference. In this cascade table for the 15 year difference show the pinch in the 20-35 year. The cascade table also shows the alternative storage of 750 $\mathrm{Mt}$ and unutilized storage of $1550 \mathrm{Mt}$. The captured $\mathrm{CO}_{2}$ of $650 \mathrm{Mt}$ presents that $29.5 \%$ of the $2,200 \mathrm{Mt}$ that can be stored in the 3 sinks. The pairing obtained sink 1 as shown in figure 9 receives $\mathrm{CO}_{2}$ only from source 4 in the 10 to 25 year timeframe and sink 2 receives $\mathrm{CO}_{2}$ only 
from source 5 in the 20 to 55 year timeframe. The grid diagram obtained the number of alternative and unutilized storage is suitable with the cascade analysis calculations so that the pairing done with this grid diagram and resulted the exact pairing.

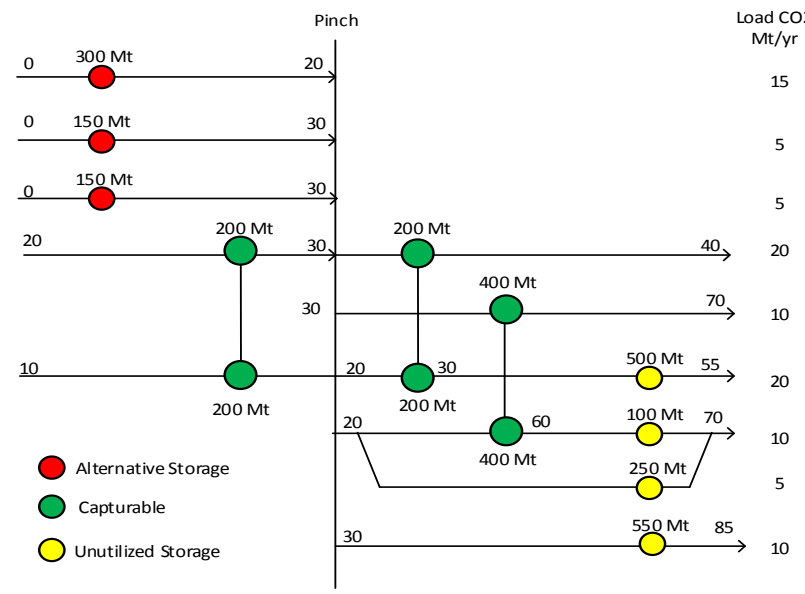

Fig. 8. CCS grid diagram with 10 year Pinch time difference

Table 6. Cascade analysis for source and sink with difference time of 15 years
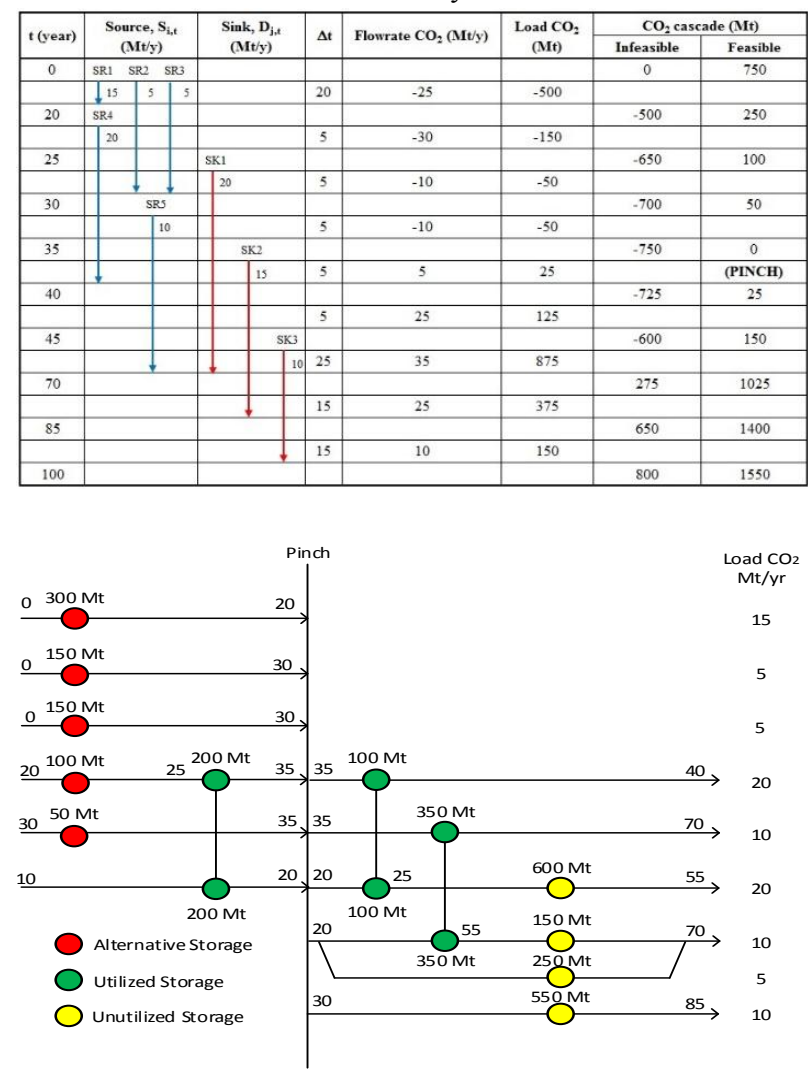

Fig. 9. CCS grid diagram with 15 year Pinch time difference

From some of the above variables, it can be concluded that the best pairing occurs when the time difference variable is 0 years. It can be seen from the percentage of carbon captured with dt 0 that is $50 \%$ larger than using other $\mathrm{dt}$ as in the table shown in table 7.

Table 7. Results calculation of CSS with pinch diagram and cascade analysis

\begin{tabular}{|c|c|c|c|c|}
\hline $\begin{array}{c}\Delta \mathbf{y} \\
\text { (year) }\end{array}$ & $\begin{array}{c}\text { Alternative } \\
\text { storage } \\
\text { (Mt) }\end{array}$ & $\begin{array}{c}\text { Carbon } \\
\text { Capturable } \\
\text { (Mt) }\end{array}$ & $\begin{array}{c}\text { Unutilized } \\
\text { storage } \\
\text { (Mt) }\end{array}$ & $\begin{array}{c}\text { \% } \\
\mathbf{C C}\end{array}$ \\
\hline 0 & 300 & 1100 & 1100 & 50 \\
\hline 5 & 450 & 950 & 1250 & 43.2 \\
\hline 10 & 600 & 800 & 1400 & 36.4 \\
\hline 15 & 750 & 650 & 1550 & 29.5 \\
\hline
\end{tabular}

\section{Conclusion}

The result from each grid diagram obtained shows the exact pairing based on the suitability of alternative and unutilized storage with composite curve and table cascade calculations. The result shows that the larger time difference the larger alternative storage and unutilized storage capacities. Therefore, having a shorter time difference will be more acceptable in the design CCS system.

The author would like to express his gratitude for the financial support from Kemenristekdikti under the contract no 582/PKS/ITS/2017

\section{References}

1. IPCC, IPCC Special Report on Carbon Dioxide Capture and Storage Intergovermental Panel on Climate Change (Cambridge University Press, New York, 2005)

2. J. A. R. Diamante, R. R. Tan, K. B. Aviso, S. Bandyopadhyay, D. K. S. Ng, D. Y. Foo, Proceedings of the 6th International Conference on Process Systems Engineering, PSE ASIA, (2013)

3. M. M. El-Halwagi, V, A.I.Ch.E. J 35, 1233-1244 (1989)

4. R. E. H. Ooi, D. C. Y. Foo, D. K. S. Ng, R. R. Tan, Che. Eng. Rsch. and Dsgn., 91, 2721-2731 (2013)

5. R. Smith, Chemical Process Design and Integration (John Wiley \& Sons, England, 2005) 